\title{
PENGEMBANGAN SISTEM INFORMASI UNTUK MEMFASILITASI PROSES ADOPSI ANJING BERBASIS WEB
}

\author{
Amelinda Chendra ${ }^{1}$, Kristina G. Simanjuntak ${ }^{2}$, Andree E. Widjaja ${ }^{3}$, Suryasari $^{4}$ \\ Mahasiswi Universitas Pelita Harapan ${ }^{1}$, Dosen Universitas Pelita Harapan ${ }^{2,3,4}$ \\ Jl. M.H. Thamrin Boulevard 1100, Lippo Karawaci, Tangerang, Banten 15811 \\ Sur-el : amelindachendra@yahoo.com ${ }^{1}$, kristinagloria.simanjuntak@gmail.com², \\ andree.widjaja@uph.edu ${ }^{3}$, suryasari.fik@uph.edu ${ }^{4}$
}

\begin{abstract}
Nowadays, the application of information systems can be applied in many fields, one of which is to support the process of adopting dog as a pet. The purpose of this research therefore is to develop an integrated information system that can be used to facilitate the process of adopting dogs. The developed information system which is web-based has several main functions, such as searching for dogs, managing adoption requests, monitoring dogs that have been adopted, and periodically managing user reports. The proposed system was developed using Rapid Application Development method, PHP programming language, Code Igniter frameworks, and MySQL database. Meanwhile, the system was tested using the black box testing method.
\end{abstract}

Keywords: facilitating dog adoption, animal defenders, information system, code igniter, rapid application development

\begin{abstract}
Abstrak : Dewasa ini, aplikasi sistem informasi dapat diterapkan di banyak bidang, salah satunya adalah dengan untuk mendukung proses adopsi hewan piaraan anjing. Tujuan dari penelitian ini adalah mengembangkan sistem informasi yang dapat digunakan untuk memfasilitasi proses adopsi anjing. Sistem informasi yang dikembangkan berbasis web ini mempunyai beberapa fungsi utama, yaitu mencari anjing adopsi, mengelola permintaan adopsi, memonitor anjing yang sudah diadopsi, dan mengelola laporan pengguna secara berkala. Sistem informasi dikembangkan menggunakan metode pengembangan sistem Rapid Application Development, bahasa pemrograman PHP, framework Code Igniter, dan database MySQL. Sedangkan hasil pengujian menggunakan metode black box testing.
\end{abstract}

Kata kunci: Fasilitasi adopsi anjing, animal defenders, sistem informasi, code ignitier, rapid application development,

\section{PENDAHULUAN}

Anjing disukai oleh banyak orang. Walaupun banyak disukai, masih banyak anjing yang ditelantarkan oleh pemiliknya. Kurangnya tanggung jawab dalam memelihara anjing inilah yang menyebabkan penelantaran anjing banyak terjadi di Indonesia. Banyak juga faktor lain yang menyebabkan penelantaran seperti faktor finansial, tempat tinggal yang tidak memadai atau tidak ada yang mengurus anjing tersebut. Tidak hanya penelantaran dan kekerasan, anjing juga seringkali diperjual-belikan untuk menjadi bahan makanan di beberapa daerah di Indonesia. Kekerasan yang dilakukan pada anjing tidak hanya dilakukan oleh mereka yang tidak menyukai anjing, tapi juga dilakukan oleh pemilik yang tidak peduli dengan anjing peliharaannya. Selain itu, sistem adopsi anjing di Indonesia kebanyakan masih dilakukan secara manual yang menyebabkan proses adopsi menjadi sulit serta memerlukan waktu yang relatif lama.

Sementara itu, pemerintah sudah membuat undang-undang, yaitu pasal 302 Kitab Undang-Undang Hukum Pidana (KUHP) yang 
mengatur tentang penelantaran dan kekerasan terhadap hewan peliharaan [1]. Namun sangat disayangkan, pada praktiknya, masyarakat maupun pemerintah kurang peduli akan kesejahteraan hidup hewan. Penelantaran dan kekerasan terhadap hewan tetap banyak terjadi di Indonesia, meskipun begitu masih ada segelintir orang yang peduli akan kesejahteraan hidup hewan. Untuk dapat membantu hewan-hewan terlantar, sekelompok orang tersebut membentuk organisasi non-profit. Salah satu contoh organisasi penyelamat hewan di Indonesia adalah Animal Defenders

Organisasi yang didirikan oleh Doni Hendaru dan teman-temannya ini merupakan bentuk kepedulian mereka terhadap banyaknya kasus penelantaran dan kekerasan terhadap hewan. Biasanya, proses penyelamatan dilakukan berdasarkan laporan warga yang kemudian diinvestigasi dan dibawa ke tempat penampungan (shelter), sedangkan untuk proses adopsi masih dilakukan secara manual [2]. Banyaknya anjing yang terlantar, terbatasnya lahan shelter, dan sedikitnya minat masyarakat untuk mengadopsi mengakibatkan masih banyak anjing terlantar yang tidak dapat ditolong oleh Animal Defenders. Memilih untuk mengadopsi dibanding membeli anjing akan membantu shelter untuk lebih cepat menangani anjinganjing yang terlantar sehingga mereka dapat cepat terselamatkan [3].

Sistem informasi yang dikembangkan khusus untuk memfasilitasi proses adopsi anjing yang berbasis web dapat memudahkan proses adopsi anjing yang masih manual, khususnya sistem yang selama ini diterapkan oleh Animal
Defenders. Sistem usulan dapat mempertemukan pengguna dalam kota yang sama yang ingin memberikan anjing dengan pengguna yang ingin mengadopsi anjing yang diinginkan tanpa biaya. Dengan tidak adanya biaya yang dikeluarkan, sistem dapat membantu pengawasan terhadap pengguna yang ingin memberikan anjing dan pengguna yang ingin mengadopsi agar tidak terjadi penelantaran maupun kekerasan terhadap anjing.

Proses adopsi anjing masih dilakukan secara manual di Indonesia. Biasanya pengadopsi harus mengumpulkan informasi anjing adopsi dari beberapa sumber untuk mencari anjing yang tersedia untuk diadopsi yang sesuai dengan keinginan. Begitu juga dengan pemberi anjing, untuk dapat memberikan anjing kepada pemilik yang sesuai masih dilakukan secara manual. Seringkali karena susahnya mencari orang yang mau mengadopsi atau mencari anjing yang sesuai keinginan untuk diadopsi, para pecinta anjing menjadi enggan untuk mengadopsi karena proses adopsi yang cukup sulit sehingga pemilik anjing yang mempunyai terlalu banyak anjing lebih memilih untuk menelantarkan anjingnya.

Selain banyaknya penelantaran, kekerasan terhadap anjing peliharaan dan aktivitas jual beli anjing untuk dimakan juga masih terjadi. Saat ini pemberi anjing masih kesulitan untuk dapat memberikan anjingnya kepada orang yang terpercaya. Pemberian anjing kepada orang yang tidak bertanggung jawab dapat berakibat buruk kepada anjing yang diadopsi. Pengawasan terhadap orang yang mengadopsi secara berkala 
masih sulit karena umumnya masih dilakukan secara manual.

Sistem informasi yang akan dikembangkan ini memiliki batasan-batasan sebagai berikut: a) Sistem ini hanya terbatas untuk mengadopsi hewan peliharaan anjing, b)Sistem ini hanya untuk digunakan di 10 daerah inti di Indonesia yaitu Jabodetabek, Surabaya, Medan, Bandung, Makassar, Semarang, Palembang, Bandar Lampung, Batam, dan Padang, dan c) Sistem yang dikembangkan adalah berbasis web.

\section{METODOLOGI PENELITIAN}

\subsection{Metodologi Penelitian}

Terdapat dua metode penelitian yang digunakan dalam penelitian ini, yaitu: Teknik pengumpulan data yang digunakan adalah wawancara dan studi literatur. Wawancara yang dilakukan adalah wawancara berencana dan dilakukan secara langsung dengan perwakilan dari organisasi penyelamat binatang Animal Defender. Sedangkan studi literatur dilakukan dengan mencari referensi teori yang terkait dengan sistem yang akan dibuat. Metodologi pengembangan sistem yang digunakan pada penelitian ini adalah Rapid Application Development (RAD), khususnya system prototyping [4]. Secara umum, urutan pelaksanaan penelitian dapat diurutkan sebagai berikut:

a. Wawancara dengan pengguna sistem (Animal Defender)

b. Studi literatur terkait topik penelitian c. Mengembangkan sistem dengan metodologi prototyping, termasuk analisa dan desain sistem

d. Iterasi prototyping sampai sistem usulan telah disetujui oleh pengguna

e. Pengujian sistem menggunakan metode Black Box Testing dan User Acceptance Test

f. Implementasi sistem

\subsection{Landasan Teori}

\subsubsection{Proses Adopsi Anjing}

Berdasarkan hasil wawancara dan studi literatur [2][3], dalam proses adopsi anjing ada beberapa hal yang harus dipertimbangkan. Salah satunya adalah calon pengadopsi harus melewati proses penyaringan oleh pemilik anjing untuk mencegah terjadinya kekerasan terhadap anjing. Tahap pertama penyaringan adalah calon pemilik anjing harus mengisi formulir yang di dalamnya terdapat sejumlah pertanyaan.

Setelah lolos dari tahap formulir, calon pemilik anjing akan diundang untuk wawancara dengan pihak shelter. Jika hasil dari wawancara dinilai meyakinkan, pihak shelter kemudian akan melakukan kunjungan rumah ke calon pemilik anjing. Jika semua proses sudah terpenuhi, maka dibuatlah surat adopsi dengan tanda tangan di atas materai untuk kedua belah pihak. Proses tersebut umumnya memakan waktu sekitar satu bulan. Namun, prosesnya tidak hanya sampai di situ, pihak shelter akan terus memantau perkembangan Anjing dengan melakukan kunjungan rumah ke pemilik anjing yang diadopsi [2]. 


\subsubsection{Unified Modeling Language (UML)}

Versi UML yang digunakan pada penelitian ini adalah UML versi 2.5. UML mempunyai dua kategori yaitu pemodelan struktural dan fungsional [4]. Pemodelan fungsional adalah pemodelan yang menggambarkan proses bagaimana sistem bekerja. Contoh dari pemodelan ini adalah use case diagram dan activity diagram. Sedangkan, pemodelan struktural adalah pemodelan yang menggambarkan struktur dan elemen dari sistem. Contoh pemodelan ini adalah class diagram.

\subsubsection{Hypertext Preprocessor (PHP)}

PHP merupakan salah satu bahasa pemrograman dan pengembangan website yang dinamis dan interaktif tidak berbayar [5]. PHP disimpan dalam bentuk extention files ".php". PHP dapat berjalan di berbagai platform seperti Windows, Linux, Unix, atau Mac OS X.

\subsubsection{Relational Database Management System} (RDBMS)

Relationship Database Management
System adalah program yang menyediakan
sistem basis data terintegrasi yang entitas
utamanya terdiri dari berbagai tabel yang berisi
berbagai field dan menggambarkan relasi antara
satu tabel ke tabel lain [6]. Setiap field dari tabel
ini berisi data yang diperlukan untuk sistem.
Dalam satu tabel terdapat satu primary key yang
merupakan kunci utama dari tabel. Basis data
mempunyai bahasa standar untuk mengakses
data dalam tabel yaitu Structured Query
Language (SQL).

\subsubsection{Model-View-Controller (MVC)}

MVC adalah framework yang menyediakan fungsi-fungsi utama untuk mengembangkan suatu website yang berfokus pada Object Oriented Programming (OOP) [7]. Ada tiga komponen utama dalam MVC, yaitu: model, views, dan controller. Model merupakan kumpulan program dari logika bisnis aplikasi yang menghubungkan dengan database. View merupakan kumpulan program untuk menampilkan user interface dari aplikasi yang terdiri dari HTML, CSS, dan javascript. Controller adalah program penghubung antara controller dan view.

Sedangkan, Code Igniter merupakan kerangka pengembangan aplikasi berbasiskan MVC yang digunakan sebagai alat untuk membangun situs web menggunakan bahasa pemrograman PHP [8]. Versi Code Igniter yang digunakan dalam penelitian ini adalah Code Igniter 3.1.7.

\subsubsection{Google Maps Geolocation}

Menurut Google Developers [9], geolocation adalah prosedur pelacakan dan pemetaan yang memungkinkan pengguna Internet lokasi geografis menggunakan HTML versi 5 dan Google Maps, kemudian menampilkan lokasi di dalam peta di web. Pengguna diidentifikasi ketika mengakses forum blog atau situs internet.Alamat IP (alamat yang dialokasikan setiap hari oleh penyedia akses internet) digunakan untuk menentukan lokasi pengunjung. Sementara itu, Google Maps API (Application Programming Interface) adalah layanan dari Google Maps yang menyediakan 
fungsi pemrograman agar Google Maps dapat diintegrasikan ke dalam web atau aplikasi yang membutuhkan layanan peta.

\subsubsection{Black Box Testing}

Ada beberapa jenis testing yang umum digunakan untuk menguji sistem, salah satunya adalah black box testing atau functional testing [4][10]. Black box testing merupakan metode pengujian sistem yang menguji apakah spesifikasi fungsional sistem sudah sesuai dengan rencana yang ditetapkan tanpa melihat source code dari sistem yang diuji tersebut.

\section{HASIL DAN PEMBAHASAN}

\subsection{Pemodelan Sistem}

Fitur dari sistem adopsi anjing dalam penelitian ini ditunjukkan melalui use case diagram yang dapat dilihat pada Gambar 1. Sedangkan, gambar 2 mengilustrasikan proses bisnis mengadopsi anjing. Setelah menentukan anjing yang sesuai untuk diadopsi, adopter mengirimkan permintaan adopsi. Kemudian, owner menerima dan melihat daftar permintaan adopsi yang diajukan adopter. Setelah meninjau permintaan adopsi, owner menentukan apakah permintaan diterima. Apabila permintaan diterima, status anjing akan berubah menjadi on progress, status adoption request menjadi accepted dan adopter akan menerima notifikasi.

Pada tahap ini dan tahap selanjutnya owner masih dapat membatalkan permintaan adopsi. Setelah itu, owner dan adopter saling berkomunikasi untuk dapat menentukan apakah anjing dan adopter cocok dan adopter dapat dipercaya.

Apabila anjing dan adopter cocok, permintaan adopsi dilanjutkan ke tahap pengiriman dan akan mengubah status permintaan jadi delivered. Pada tahap ini, owner menyerahkan anjingnya ke adopter. Setelah anjing sampai, adopter melakukan konfirmasi dengan menekan tombol accepted. Status dog dan permintaan akan berubah menjadi adopted. Class diagram dari sistem adopsi anjing ditunjukkan pada Gambar 3 yang ditempatkan di bagian paling terakhir artikel ini.

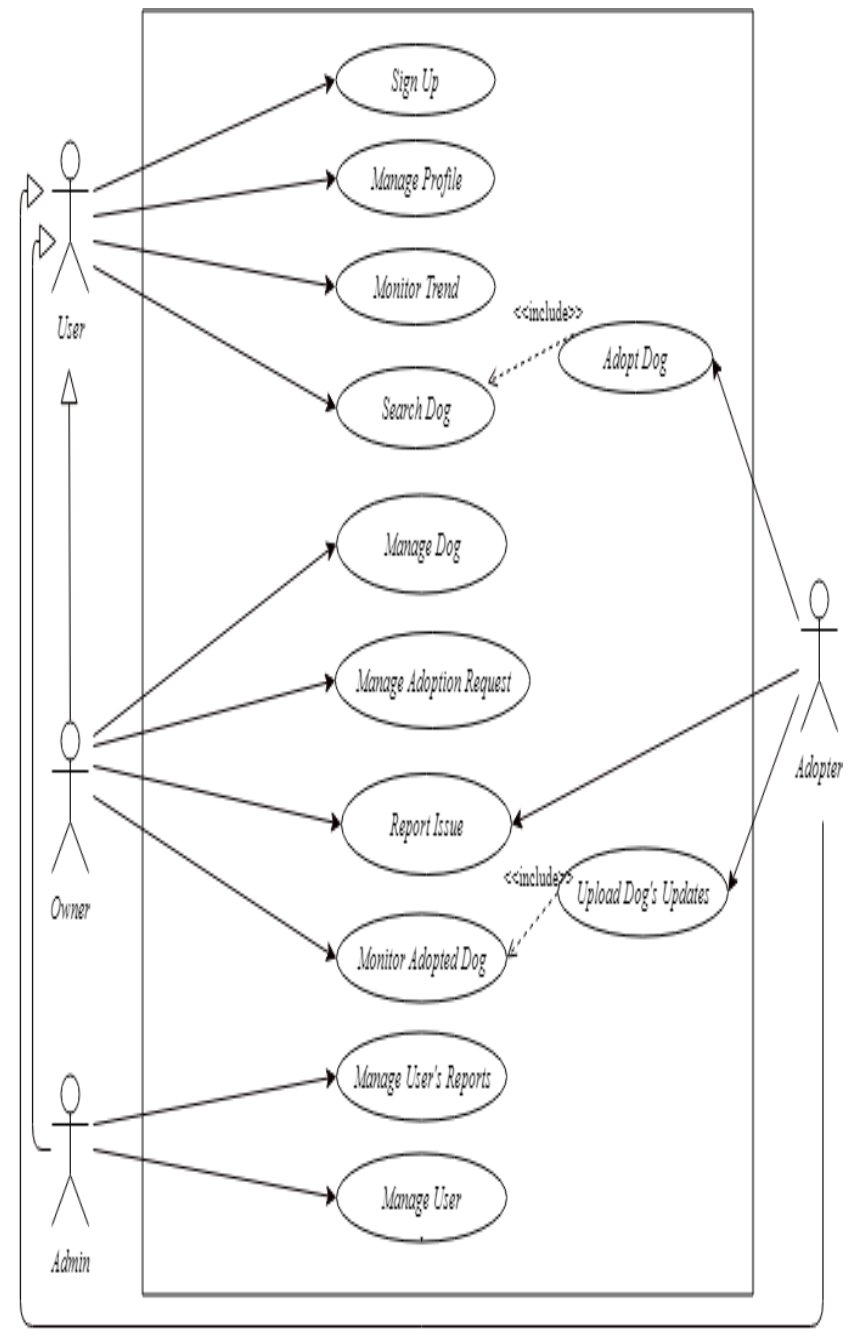

Gambar 1. Use case diagram sistem adopsi anjing 


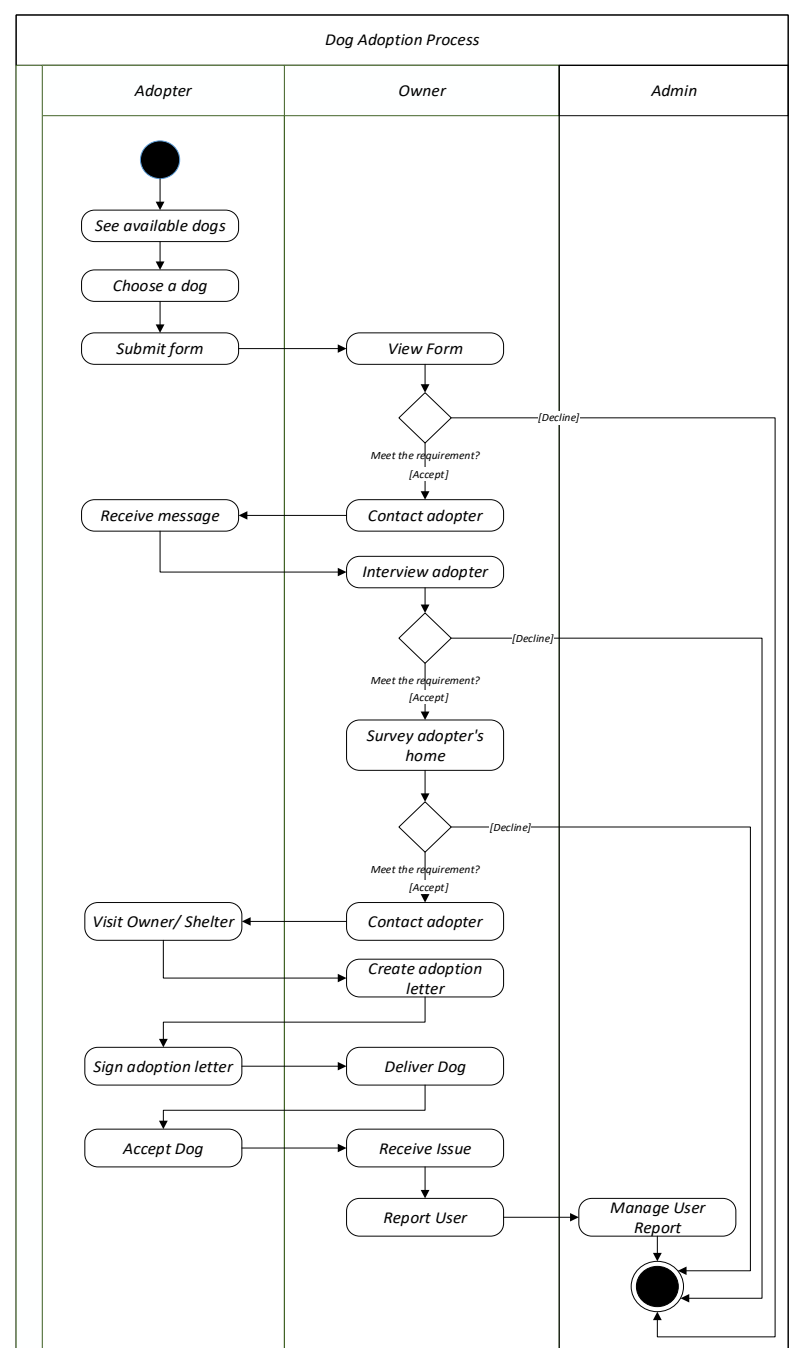

Gambar 2. Proses Bisnis Adopsi Anjing

\subsection{Perancangan Lapisan Antarmuka}

Gambar 4 di bawah ini merupakan tampilan halaman utama (landing page) dari sistem berbasis website ini.

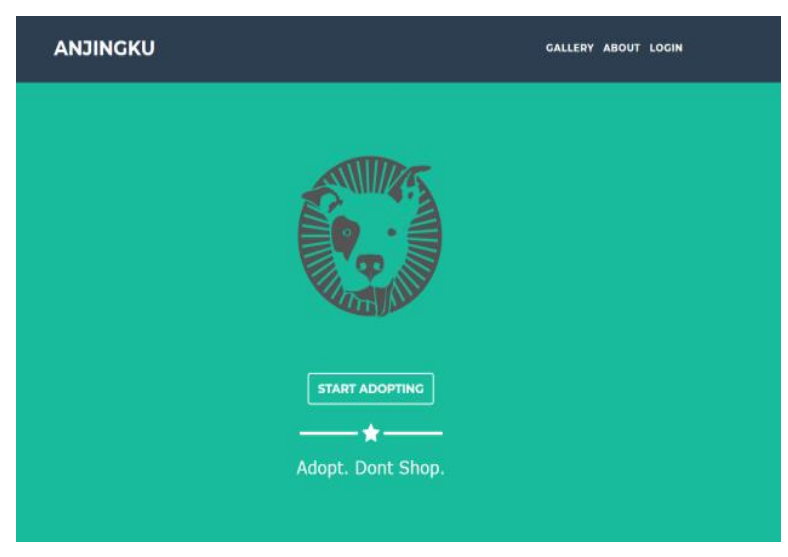

Gambar 4. Halaman Utama
Tampilan untuk mendaftarkan akun user pertama kali dapat dilihat pada gambar 5 .

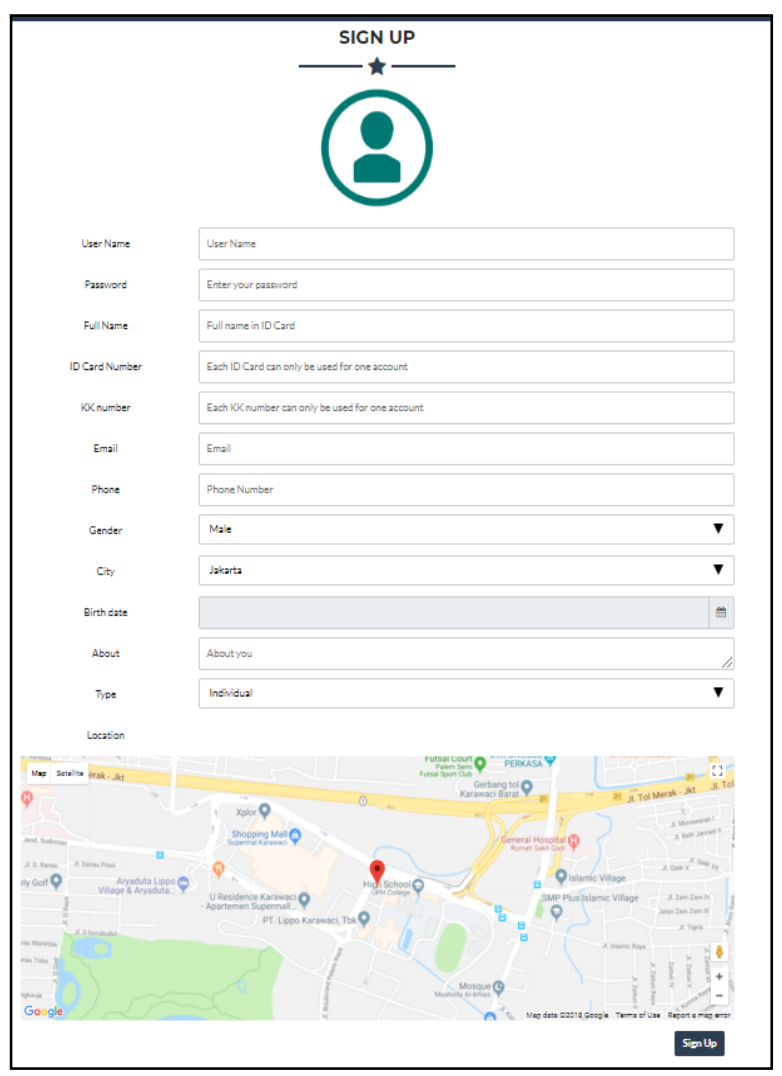

\section{Gambar 5. Halaman Sign-up}

Jika ingin mencari anjing yang ingin diadopsi, user dapat menggunakan halaman search dog. Kemudian jika pengguna sudah menemukan anjing yang cocok, dapat dilanjutkan ke proses selanjutnya untuk mengadopsi anjing dengan menggunakan form adopt dog .

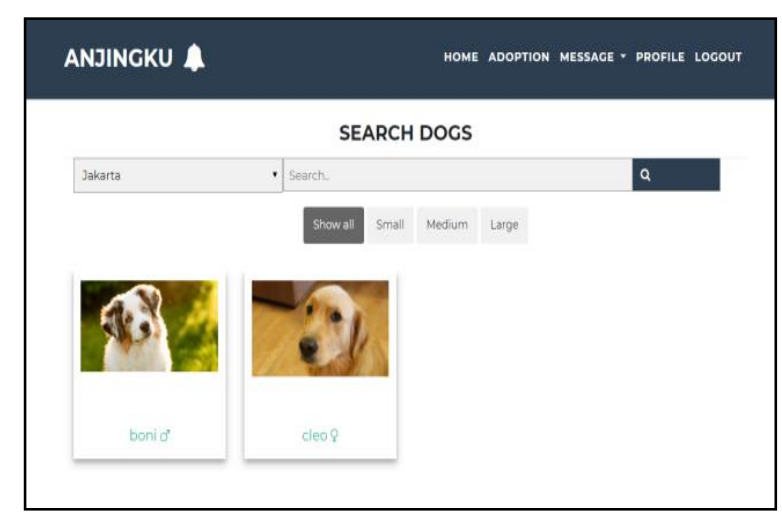

Gambar 6. Halaman Search Dog 


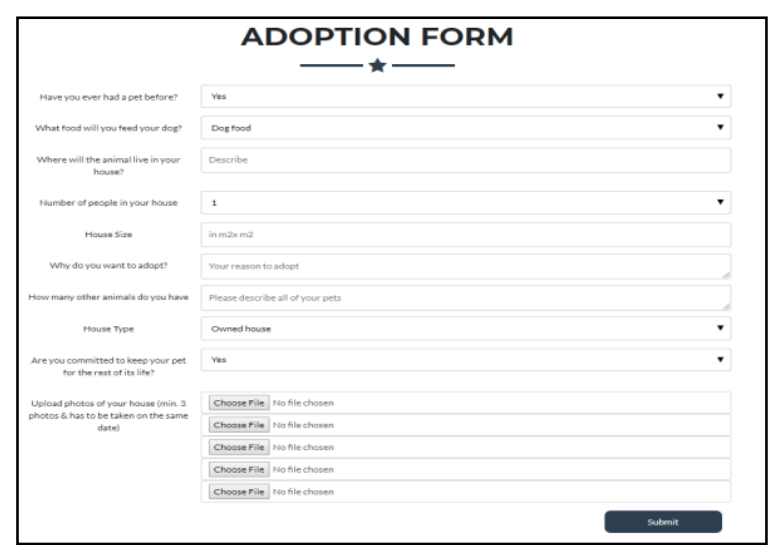

Gambar 7. Halaman Adopt Dog

Pemilik (owner) dari anjing yang ingin diadopsi dapat melihat permintaan (request) dari pengguna yang mau mengadopsi anjing tersebut melalui halaman adoption request yang dapat dilihat pada gambar 8 , dan rincian informasi dari adoption request tersebut dapat dilihat pada gambar 9.

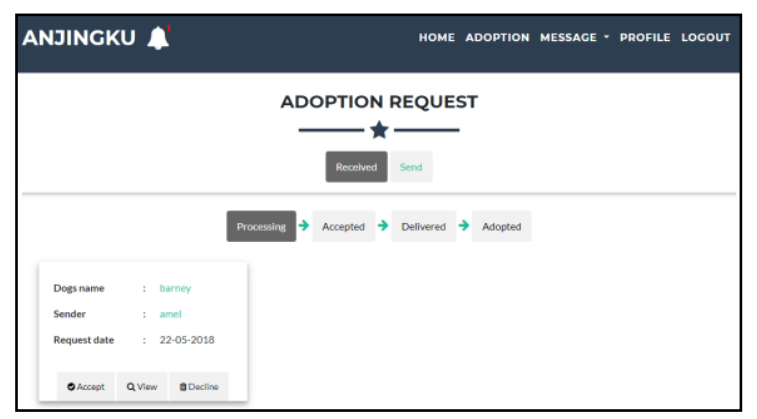

Gambar 8. Halaman Adoption Request

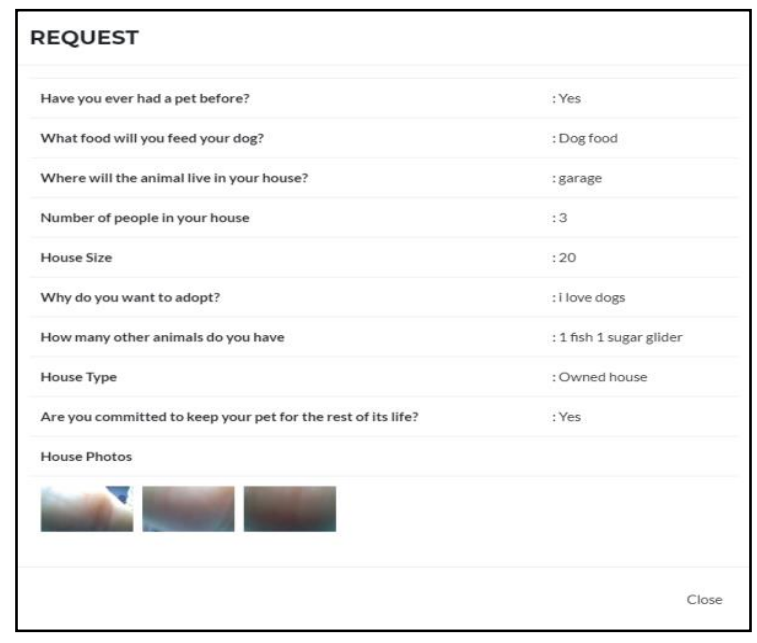

Gambar 9. Rincian dari Adoption Request

\subsection{Pengujian Sistem}

Pengujian sistem adopsi anjing berbasis web ini dilaksanakan dengan metode black-box testing [10]. Dalam pengujian ini, pengguna akan diminta untuk menguji apakah setiap skenario dan fungsi sistem berjalan dengan baik. Pengguna akan diminta melakukan test action berdasarkan skenario tes, lalu mengisi pass di kolom status apabila kondisi yang diujikan berjalan dengan baik dan expected results terpenuhi, dan mengisi failed apabila expected results tidak terpenuhi.

Skenario yang dites terdiri dari: Sign up, manage profile, monitor trend, manage dog's profile, manage adoption request, monitor adopted dog, upload dog's updates, search dog, adopt dog, report issue, manage user's reports, dan manage user. Berikut ini adalah contoh black box testing untuk skenario tes manage user.

\section{Scenario: Manage User}

Scenario Description:

Pengujian ini bertujuan untuk menjelaskan proses mengelola aktivasi pengguna.

Test Scripts:

Manage user

Use Case:

Manage user

Use Groups:

Admin

Script: Manage User

Script Description:

Test Script ini menjelaskan mengenai proses mengelola status akun pengguna.

\section{Setup:}

1) User telah login ke dalam website

2) User sedang mengakses halaman suspend user

\section{Script Steps}

Tabel 1 dapat dilihat di akhir halaman. 


\section{KESIMPULAN}

Berdasarkan rumusan masalah dan tujuan penelitian, hasil dari penelitian ini adalah sistem adopsi anjing berbasis web. Sistem informasi ini telah dirancang dan disesuaikan dengan kebutuhan objek penelitian yaitu Animal Defenders. Pengujian sistem yang telah dilakukan langsung oleh pengguna (perwakilan Animal Defenders) telah berjalan dengan baik.

Dengan adanya sistem ini, diharapkan dapat membantu mengurangi kasus penelantaran anjing. Adapun sistem adopsi anjing berbasis webini dapat memfasilitasi hal-hal sebagai berikut:

a. Mempertemukan owner dengan calon adopter yang sesuai untuk mengadopsi anjingnya. Owner hanya perlu mengunggah informasi anjingnya ke dalam sistem dan adopter akan mengirimkan permintaan adopsi.

b. Mempermudah pengawasan proses adopsi yang sebelumnya dilakukan secara manual menjadi lebih praktis. Ketika mengadopsi, sistem mengharuskan adanya konfirmasi kedua pihak bahwa anjing adopsi telah diserahkan dan adopter telah menerima anjing yang telah diserahkan untuk menyelesaikan proses adopsi.

c. Membantu pengawasan terhadap anjing yang diadopsi dengan melihat update informasi terbaru yang dikirim oleh adopter yang harus dikirim minimal sebulan sekali. Pengguna yang tidak mengirim update dalam sebulan akan mendapat notifikasi agar mengunggah update terbaru anjing. d. Melaporkan pengguna yang bermasalah kepada admin. Admin dapat menindaklanjut dengan menangguhkan akun pengguna agar pengguna tidak dapat melakukan proses adopsi di dalam sistem lagi.

e. Menyediakan data trend di dalam sistem mengenai adopsi anjing dan kasus penelantaran anjing dalam bentuk chart, seperti jumlah anjing yang sudah diadopsi dan diselamatkan, persentase jenis kelamin, ukuran dan area anjing, persentase alasan penyelamatan, dan persentase laporan masalah yang diadukan pengguna.

Sementara itu, sistem ini tidak luput dari kekurangan dan masih dapat dikembangkan lagi selanjutnya. Adapun saran yang dapat diusulkan untuk pengembangan sistem selanjutnya adalah:

a. Pengembangan aplikasi berbasis mobile agar dapat lebih mudah diakses oleh pengguna.

b. Menambah validasi yang lebih rinci, seperti memeriksa apakah nomor KTP (Kartu Tanda Penduduk) dan nomor KK (Kartu Keluarga) terdaftar di data pemerintah.

c. Penambahan jenis hewan yang dapat diadopsi.

d. Memperluas jangkauan tempat yang dapat menggunakan sistem ini.

e. Penambahan fitur untuk dapat mendeteksi lokasi anjing terdekat. 


\section{DAFTAR PUSTAKA}

[1] T. J. A. Pramesti, "Jerat Hukum Penganiaya Binatang", Hukumonline.com. [Online]. Available: http://www.hukumonline.com/klinik/detail /lt5181e7cb577f6/jerat-hukumpenganiaya-binatang. [Accessed: 13-Jul2019].

[2] A. Meodia, "Berniat adopsi anjing? Ini tahapannya", Antaranews. [Online]. Available:

http://www.antaranews.com/berita/495436 /berniat-adopsi-anjing-ini-tahapannya.

[Accessed: 13-Jul-2019].

[3] C. Lazuardi, "Mengapa mengadopsi anjing lebih baik dibanding membeli?", Brillio.net. [Online]. Available: https://www.brilio.net/creator/mengapamengadopsi-anjing-lebih-baik-dibandingmembeli-8883be.html. [Accessed: 13-Jul2019].

[4] A. Dennis, B. H. Wixom, and D. Tegarden, Systems Analysis and Design: An Object-Oriented Approach with UML, $5^{\text {th }}$ ed. USA: John Wiley \& Sons, 2015.

[5] B. Nugroho, Aplikasi Pemrograman Web Dinamis dengan PHP dan MySQL. Yogyakarta: Gava Media, 2019.

[6] T. Connolly and C. Begg, Database Systems: A Practical Approach to Design, Implementation, and Management, $6^{\text {th }}$ ed. USA: Pearson, 2015.

[7] C. Pitt, PRO PHP MVC. New York: Apress, 2010.

[8] D. Upton, CodeIgniter for Rapid PHP Application Development. UK: Packt Publishing, 2007.

[9] Google Developers, "Google Maps API", Google. [Online]. Available: https://developers.google.com/maps/docu mentation/directions/intro?hl=id. [Accessed: 13-Jul-2019].

[10] I. Sommerville, Software Engineering, $9^{\text {th }}$ ed. USA: Addison-Wesley, 2011. 


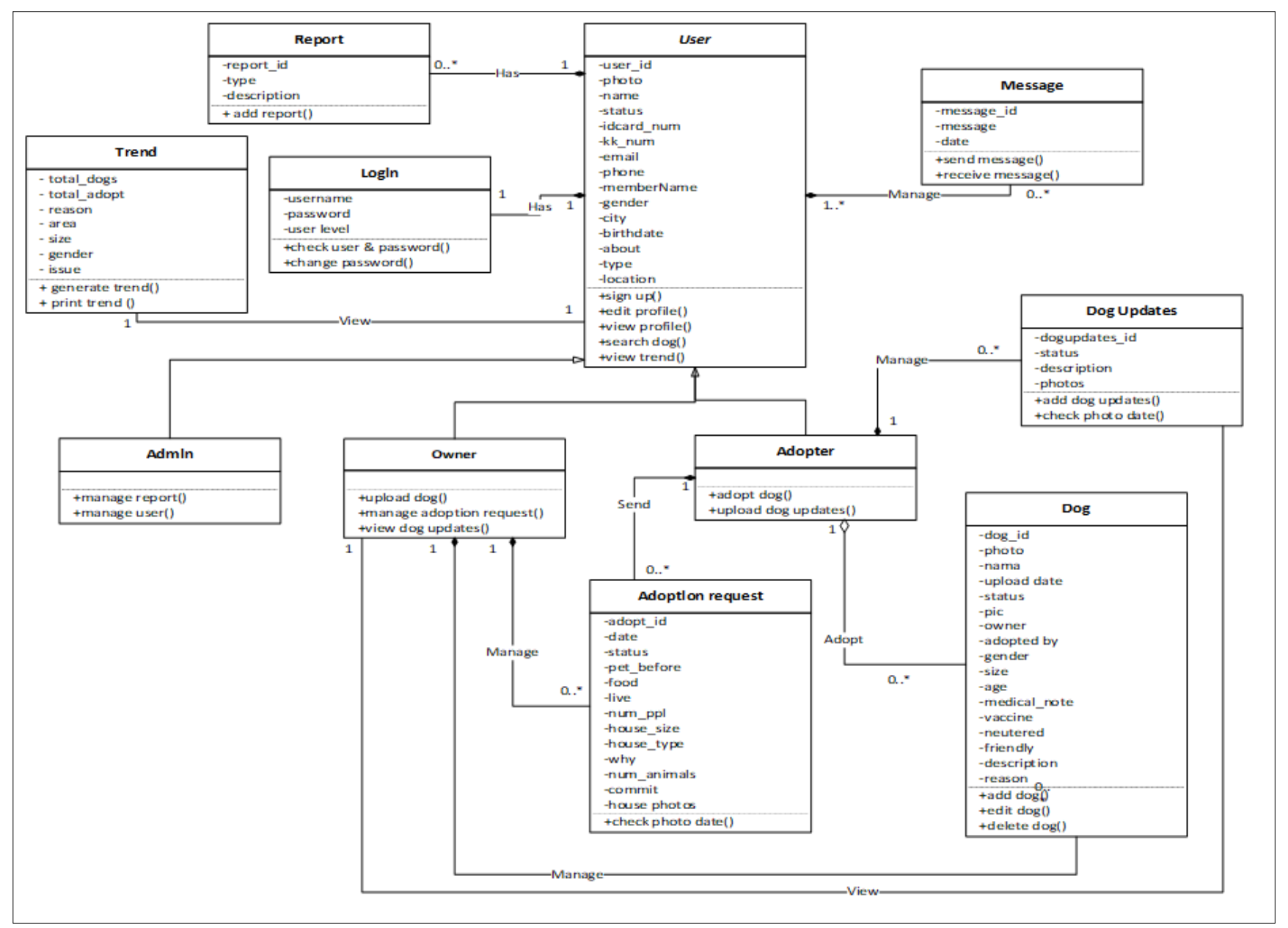

Gambar 3. Class Diagram Sistem Adopsi Anjing

Tabel 1. Test Scripts Skenario Manage User

\begin{tabular}{|l|l|l|l|l|}
\hline Step & Test Action & Expected results & Status & Reference \\
\hline 1 & $\begin{array}{l}\text { Admin memilih } \text { menu suspend } \\
\text { user }\end{array}$ & $\begin{array}{l}\text { Sistem menampilkan } \\
\text { pengguna yang terdaftar }\end{array}$ & Pass & 4.101 \\
\hline 2 & $\begin{array}{l}\text { Admin memilih } \text { user yang } \\
\text { ingin dinonaktifkan dan } \\
\text { menekan tombol suspend }\end{array}$ & $\begin{array}{l}\text { Sistem menampilkan pop-up } \\
\text { konfirmasi dan notifikasi } \\
\text { bahwa status } \text { user berhasil } \\
\text { diperbaharui }\end{array}$ & Pass & $\begin{array}{l}\text { Gambar } \\
4.99, \\
\text { Gambar } \\
4.103\end{array}$ \\
\hline 3 & $\begin{array}{l}\text { Admin memilih } \text { user yang } \\
\text { ingin diaktifkan dan menekan } \\
\text { tombol activate }\end{array}$ & $\begin{array}{l}\text { Sistem menampilkan } \\
\text { notifikasi bahwa status } \text { user } \\
\text { berhasil diperbaharui }\end{array}$ & Pass & $\begin{array}{l}\text { Gambar } \\
4.103\end{array}$ \\
\hline $\begin{array}{l}\text { Admin memilih } \text { user yang } \\
\text { ingin dijadikan sebagai } \text { admin } \\
\text { dan memilih tombol } \text { set as } \\
\text { admin }\end{array}$ & $\begin{array}{l}\text { Sistem menampilkan } \\
\text { notifikasi bahwa status } \text { user } \\
\text { berhasil diperbaharui }\end{array}$ & Pass & $\begin{array}{l}\text { Gambar } \\
4.103\end{array}$ \\
\hline
\end{tabular}

